\title{
AVALIAÇÃO DA QUALIDADE DOS FRUTOS DE FUNCHO (Foeniculum vulgare Mill.) UTILIZADOS NO PREPARO DE CHÁS
}

\section{EVALUATION OF QUALITY OF FALSE-FENNEL (Foeniculum vulgare Mill.) USED IN THE PREPARATION OF TEA}

\author{
Jessica de Paula ${ }^{1}$ \\ Roberta Aparecida de Sousa ${ }^{1}$ \\ Renato Farina Menegon ${ }^{2}$ \\ Walderez Moreira Joaquim ${ }^{3}$ \\ luri Rojahn da Silva ${ }^{4}$
}

RESUMO: A espécie Foeniculum vulgare Mill. conhecida popularmente como funcho ou falsa erva-doce, apresenta óleos essenciais em sua composição, onde está contido o princípio ativo que caracteriza a ação estomática, diurética, carminativa, anti-inflamatória, bactericida e espasmolítica da planta. Por esses efeitos, pelo seu fácil acesso à população e pelo baixo custo, foi verificado que seu consumo vem aumentando significativamente entre a população e, diante disso, observa-se a necessidade de intensificar a fiscalização quanto ao controle da qualidade desses chás, objetivando maior segurança no uso e maior garantia dos efeitos desejados. A qualidade de amostras de funcho, comercializadas na cidade de São José dos Campos, foi avaliada por determinação de material estranho, determinação do teor de óleos essenciais, determinação de umidade e cinzas totais, além da análise das informações contidas nos rótulos. Para esses testes, foram adquiridas 5 marcas comerciais diferentes da erva, comercializadas em diferentes estabelecimentos da cidade. Parte das amostras analisadas estava em desacordo com a legislação vigente e com a Farmacopéia Brasileira $5^{a}$ Ed., destacando as falhas quanto ao controle de qualidade desses produtos em todos os aspectos analisados.

Palavras-chave: Foeniculum vulgare; produto natural; controle de qualidade; funcho.

ABSTRACT: The species Foeniculum vulgare Mill., popularly known as fennel or false-fennel, has essential oil in its composition. The active compounds of this plant possess stomatal, diuretic, carminative, anti-inflammatory, antibacterial, and spasmolytic activities. Due to these actions and the low costs that has made the consumption of natural products accessible to everyone, the increased use of this herb is significant. Therefore, the control and supervision of the quality must be intensified to assure the safe use and the desired action of the tea. The quality of false-fennel samples purchased in the city of São José dos Campos was evaluated for percentage of foreign material, quantity of essential oils, moisture and total ash determinations, and label information. Five different brands purchased in various locations of the city were used in this study. Part of the analyzed samples was not in accordance with the current laws and the Brazilian Pharmacopoeia $5^{\text {th }}$ Ed. This highlights deficiencies at the quality control of these products in all analyzed aspects.

Keywords: Foeniculum vulgare; natural product; quality control; false-fennel.

\footnotetext{
1 Graduandas em Farmácia - Universidade do Vale do Paraíba - Univap. E-mails: je_paula_15@hotmail.com; roberta.sousa@ymail.com.

${ }^{2}$ Doutor em Ciências Farmacêuticas - Universidade Estadual Paulista Júlio de Mesquita Filho - UNESP e Professor Adjunto da Universidade Federal de São Paulo - Unifesp. E-mail: renato.farina@yahoo.com.br.

${ }^{3}$ Doutora em Ciências Biológicas - Botânica - UNESP e Professor Integral da Univap. E-mail: wal@univap.com.

${ }^{4}$ Mestre em Meteorologia - Instituto Nacional de Pesquisas Espaciais - INPE. E-mail: iuri@univap.br.
} 


\section{INTRODUÇÃO}

Dentre os vários usos das plantas, estas podem ser utilizadas como matériasprimas para a produção de medicamentos e, também, em práticas populares e tradicionais, como remédios caseiros e comunitários, processo conhecido como medicina tradicional. A Organização Mundial da Saúde (OMS) reconhece que grande parte da população dos países em desenvolvimento depende da medicina tradicional para sua atenção primária, tendo em vista que $80 \%$ dessa população utilizam práticas tradicionais nos seus cuidados básicos de saúde e $85 \%$ destes utilizam plantas ou preparações destas (BRASIL, 2006).

A tendência de aumento do consumo de plantas medicinais em todo o mundo pode ser explicada, segundo Lucca et al. (2010), por vários fatores, como o alto custo dos medicamentos industrializados, os efeitos indesejáveis dos medicamentos sintéticos e do próprio modismo, já que, muitas vezes, as plantas medicinais são apresentadas como milagrosas e totalmente isentas de efeitos colaterais (MARREIRO; TEIXEIRA; SOUZA, 2010). As plantas medicinais são comumente utilizadas por seus efeitos terapêuticos sob a forma de chás, que é o modo mais usual de consumo pela população, sendo comercializados em mercados populares, feiras livres, farmácias e ervanarias.

De acordo com Zaroni et al. (2004), esse aumento na procura de plantas medicinais frente à sua oferta insuficiente, conduziu a uma queda de sua qualidade. Muitos produtores desconhecem os cuidados que se deve ter nas diversas etapas para a obtenção de matérias-primas e/ou produtos de qualidade adequada, e não contam com a orientação de profissionais capacitados. Diante desse conhecimento, é importante que haja uma maior fiscalização no controle da qualidade dos chás comercializados. No entanto, observa-se, no mercado que a maioria desses produtos está registrada no Ministério da Agricultura e do Abastecimento (MAPA), como alimentos e não como medicamentos junto ao Ministério da Saúde, o que os submeteriam às normas da Agência Nacional de Vigilância Sanitária (ANVISA), de modo que a fiscalização da qualidade seja bastante prejudicada, pois não leva em consideração a qualidade terapêutica desses produtos.

A RDC no 48/2004, que estabelece normas para o registro de medicamentos fitoterápicos no Brasil, permite o registro como fitoterápico apenas dos derivados da droga vegetal, que é o produto de extração da matéria-prima vegetal: extrato, tintura, óleo, cera, exsudato, suco etc. De acordo com a abrangência, "não é objeto de registro ou cadastro a planta medicinal ou suas partes, após processos de coleta, estabilização e secagem, podendo ser íntegra, rasurada, triturada ou pulverizada". Ou seja, drogas vegetais não são consideradas como medicamentos, mas um simples chá (LUCCA et al., 2010; BRASIL, 2010).

Uma das plantas medicinais mais utilizadas pela população brasileira é o funcho (Foeniculum vulgare Mill., Apiaceae), também conhecida como falsa erva-doce ou anis-doce. É uma erva aromática e condimentar (LORENZI; MATOS, 2008), perene e bienal, entouceirada, aromática, nativa da região mediterrânea que encontrase em terrenos baldios. A variedade amarga é espontânea no norte e centro do continente e a variedade doce é cultivada 
em todo o mundo (CUNHA; DA SILVA; ROQUE, 2004). As principais propriedades farmacêuticas atribuídas ao óleo essencial do fruto do funcho são ações carminativa e eupéptica, nas cólicas abdominais, expectorante e antiespasmódica, na bronquite e asma, e, ainda, a ação antiinflamatória, diurética e anti-séptica (TINOCO; MARTINS; CRUZ-MORAIS, 2007). Na culinária, os frutos, denominados, popularmente, de sementes, são utilizados para condimentar e aromatizar pães, bolos e biscoitos. Além disso, o óleo essencial é utilizado na cosmética e perfumaria (CARVALHO et al., 2011).

O objetivo deste trabalho foi analisar a qualidade dos frutos de funcho para o preparo de chá, a fim de se verificar os teores de óleo essencial, umidade, cinzas totais, matéria estranha e observar as informações contidas no rótulo, comparando-se com os padrões farmacopeicos estabelecidos pela Farmacopéia Brasileira 5aㅗ Edição (BRASIL, 2010).

\section{METODOLOGIA}

Obtenção e preparo das amostras

As amostras de funcho (Foeniculum vulgare Mill.) foram adquiridas no comércio da região central da cidade de São José dos Campos - SP, no mês de março de 2012. Sendo 4 marcas aleatórias de chá (amostras $01,02,03,04)$ e uma amostra de frutos a granel (amostra 05) (Tabela 01).

Para o preparo das amostras, utilizouse como referência os Métodos de Análises de Drogas Vegetais da $5^{\underline{a}}$ Edição da Farmacopéia Brasileira (BRASIL, 2010), considerando-se todos os aspectos de amostragem ali preconizados.
Tabela 1 - Apresentação das amostras de funcho (Foeniculum vulgare)

\begin{tabular}{cc}
\hline Amostra & Apresentação \\
\hline 01 & Granel \\
02 & Granel \\
03 & Sachê \\
04 & Granel \\
05 & Sachê \\
\hline
\end{tabular}

Determinação de matéria estranha

Após a preparação da amostra, foi realizada a determinação de matérias estranhas presentes nas amostras de funcho. A amostra foi espalhada em uma camada fina sobre superfície plana. Separou-se, então, manualmente, os materiais estranhos à amostra, como caules, insetos, pontos pretos, poeira e folhas de outras plantas, inicialmente a olho nu e, em seguida, com auxílio de lente de aumento (aumento de cinco a dez vezes). Pesou-se o material separado e determinou-se sua porcentagem com base na massa da amostra submetida ao ensaio.

\section{Determinação do teor de óleos essenciais}

Esse procedimento foi realizado empregando-se aparelho de Clevenger, a partir de 20 gramas de amostra de funcho, previamente triturada. $100 \mathrm{~mL}$ de água destilada foram empregados para a hidrodestilação do óleo essencial. A destilação seguiu-se por quatro horas após início da ebulição.

\section{Determinação de umidade}

$\mathrm{Na}$ determinação de umidade, as amostras foram trituradas de forma a limitar a dimensão de seus componentes a, no máximo, $3 \mathrm{~mm}$ de espessura. 
Utilizou-se o método de perda por dessecação onde foram transferidos $2 \mathrm{~g}$ de amostra preparada, para vidro de relógio, previamente dessecado nas mesmas condições a serem adotadas para a amostra, ou seja, a temperatura entre $100 \mathrm{e}$ $105^{\circ} \mathrm{C}$, durante 30 minutos, quando não foi observada variação no peso do vidro de relógio. A amostra foi dessecada a 100 $105^{\circ} \mathrm{C}$, durante 5 horas, até peso constante. Calculou-se, então, a porcentagem de água em relação à amostra seca. A concentração previamente calculada de óleos essenciais, em cada amostra, foi descontada da massa total perdida no processo de dessecação.

\section{Determinação de cinzas totais}

Para a determinação de cinzas totais, o método consistiu na pulverização de $2 \mathrm{~g}$ da amostra e posterior transferência para um cadinho de porcelana, previamente tarado e submetido às mesmas condições do ensaio. A amostra foi carbonizada na chama de um bico de Bunsen e incinerada em mufla com temperatura entre $550^{\circ} \mathrm{C}$ e $600^{\circ} \mathrm{C}$ até que todo o carvão fosse eliminado. $O$ cadinho foi resfriado em dessecador e, então, pesado. A porcentagem de cinzas foi calculada em relação à amostra seca.

\section{Análise de rótulos}

De acordo com a RDC no 259, de 20 de setembro de 2002 , da ANVISA, os rótulos das embalagens de chás devem conter: Nome do Fabricante; Logomarca da Empresa; Endereço Completo; CNPJ; Lote; Fabricação; Validade; Presença da Frase "Indústria Brasileira" no Painel Frontal; Categoria do Produto (conteúdo); Nomenclatura Botânica; Tabela Nutricional;
Proteção da Luz; "Informação Referente ao Glúten"; Peso Indicado no Painel Frontal; Designação "Chá de Erva-doce"; Instruções de Preparo; Indicação Medicamentosa e/ou Terapêutica; Idioma Português; Frase "Isento de Registro" e Armazenamento de Um Ano. As embalagens das amostras foram inspecionadas quanto ao cumprimento dessa resolução.

\section{RESULTADOS E DISCUSSÃO}

\section{Determinação de matéria estranha}

Segundo a 5aㅡ Edição da Farmacopéia Brasileira (Brasil, 2010), são permitidos até $2 \%$ de matérias estranhas em amostras de erva-doce (Pimpinella anisum - Apiaceae). Foi verificado que, nas amostras de funcho (Foeniculum vulgare) analisadas, 40\% das amostras apresentavam teor de material estranho acima do permitido (Tabela 2).

Os materiais estranhos presentes nas amostras analisadas constituíram-se em sua maioria de caules, sendo que, nas amostras 01, 02 e 04 (a granel), constatou-se, também, a presença de terra seca, partes de outras plantas, larvas e insetos. Não foi possível fazer uma análise mais criteriosa para verificar outros tipos de matérias estranhas presentes nas amostras em sachê (amostras 03 e 05), porque estas se apresentaram muito trituradas, 0 que dificultou sua análise.

A determinação de matérias estranhas é importante, pois indica falhas de Boas Práticas de Fabricação que pode constituir em risco a população que faz uso deste tipo de produto, tanto para fins medicamentosos quanto alimentícios. Como atualmente grande parte dessa população é encorajada a consumir plantas medicinais, por serem naturais e ditas seguras, acabam-se 
deparando com efeitos adversos, que podem desencadear desde reações alérgicas e até mesmo choque anafilático, como relatado por Falkowskiq, Jacomassi e
Takemura (2009). Além disso, pode ocorrer contaminação devido a agrotóxicos, metais pesados e microrganismos (WHO, 2004 apud BALBINO; DIAS, 2009).

Tabela 2 - Porcentagem de material estranho encontrado nas amostras de funcho (Foeniculum vulgare)

\begin{tabular}{clc}
\hline Amostra & \multicolumn{1}{c}{ Material estranho } & $\%$ \\
\hline $01-$ granel & Caules, formigas, pontos pretos, poeira e folhas de outras plantas & 1,4 \\
$02-$ granel & Caules, pontos pretos e poeira & 2,3 \\
03 - sachê & Caules & 1,5 \\
$04-$ granel & Caules & 1,1 \\
05 - sachê & Caules, larva viva de inseto, inseto morto, poeira e folhas de & 2,8 \\
& outras plantas & \\
\hline
\end{tabular}

Determinação do teor de óleos essenciais

Segundo a Farmacopéia Brasileira 5 Edição (BRASIL, 2010), o óleo essencial, ou óleo volátil, deve estar presente na concentração mínima de $2 \%$ para erva-doce ( $P$. anisum), sendo seu principal constituinte o anetol (85\%). Verificou-se que as amostras 02, 03 e 05 (Tabela 3) apresentaram teor de óleo essencial abaixo desse valor mínimo preconizado. O baixo teor de óleo essencial encontrado nas amostras analisadas possivelmente pode ser explicado pelo excesso de trituração de algumas amostras, bem como falhas em seu armazenamento, o que pode causar uma maior volatilização do óleo essencial.

Esse baixo teor encontrado nas amostras indica que seu uso terapêutico na forma de chá pode estar comprometido, uma vez que o óleo essencial contém o princípio ativo desse vegetal, o anetol (BRASIL, 2010). Seu uso, dessa forma, não irá garantir os efeitos que se caracterizam por ação estomática, diurética, carminativa, além do favorecimento da lactação, ação anti-inflamatória, bactericida e espasmolítica (RAMOS, 2003).
Tabela 3 - Porcentagem de óleos essenciais nas amostras de funcho (Foeniculum vulgare)

\begin{tabular}{lc}
\hline \multicolumn{1}{c}{ Amostra } & $\%$ \\
\hline 01 - granel & 2 \\
02 - granel & 1,5 \\
03 - sachê & 0,5 \\
04 - granel & 2 \\
05 - sachê & 0,5 \\
\hline
\end{tabular}

Determinação de umidade

Conforme as porcentagens de umidade obtidas para cada amostra analisada (Tabela 4), constatou-se que todas as amostras foram reprovadas. As amostras ultrapassaram o teor máximo de umidade (7\%), estabelecido pela $5^{\text {a }}$ Edição da Farmacopéia Brasileira (BRASIL, 2010), para a erva-doce ( $P$. anisum). $O$ excesso de umidade em matérias-primas vegetais permite a ação de enzimas, podendo acarretar a degradação de constituintes químicos, além de possibilitar o desenvolvimento de fungos e bactérias (SIMÕES et al., 2007).

O desenvolvimento de microrganismos pode ser prejudicial ao consumidor, podendo gerar intoxicações e disseminação de 
infecções além da degradação dos constituintes químicos, acarretar alterações no aroma e sabor do chá, bem como não possuir o efeito terapêutico esperado.

\section{Tabela 4 - Teor de Umidade encontrado nas amostras de funcho (Foeniculum vulgare)}

\begin{tabular}{ll}
\hline \multicolumn{1}{c}{ Amostra } & $\%$ \\
\hline 01 - granel & 11 \\
02 - granel & 12 \\
03 - sachê & 12 \\
04 - granel & 12 \\
05 - sachê & 15 \\
\hline
\end{tabular}

Determinação de cinzas totais

A determinação de cinzas totais permite a verificação de impurezas inorgânicas não-voláteis que podem estar presentes como contaminantes (SIMÕES et al., 2007) e, assim, indicar a presença de possíveis adulterações. A Farmacopéia Brasileira, em sua $5^{\text {a }}$ Edição (BRASIL, 2010), preconiza que o valor máximo de cinzas que podem ser encontrados em amostras é de até $12 \%$. Como demonstrado na Tabela 5, apenas a amostra número 05 apresentou irregularidade, com teor de cinzas de $13 \%$.

Tabela 5 - Teor de Cinzas Totais encontrada nas amostras de funcho (Foeniculum vulgare)

\begin{tabular}{lc}
\hline \multicolumn{1}{c}{ Amostra } & $\%$ \\
\hline 01 - granel & 10 \\
02 - granel & 9 \\
03 - sachê & 12 \\
04 - granel & 10 \\
05 - sachê 05 & 13 \\
\hline
\end{tabular}

De modo a complementar os resultados encontrados na determinação de cinzas totais, a determinação de cinzas insolúveis em ácidos e de cinzas sulfatadas poderiam trazer importantes informações adicionais, como a presença de impurezas inorgânicas e metálicas. Entretanto, este trabalho buscou realizar apenas ensaios descritos na monografia específica contida na Farmacopéia Brasileira 5ํㅡㄹ Ed. Uma vez que tais ensaios não estão previstos, não temos valores oficiais de limites aceitáveis, de modo que se optou por não realizá-los.

\section{Análise de rótulos}

A Agência Nacional de Vigilância Sanitária (BRASIL, 2008) determina os rótulos como "elementos essenciais de informação entre produto e consumidores e visam à garantia de qualidade e saúde do consumidor". De acordo com a legislação referente a rotulagem presentes na $5^{\text {a }}$ Edição da Farmacopéia Brasileira (BRASIL, 2010), e da RDC no 259, de 20 de setembro de 2002, da ANVISA, foi verificado que todas as marcas estavam regulares nos seguintes itens: Nome do Fabricante, Logomarca da Empresa, Endereço Completo, CNPJ, Validade, Categoria do Produto (conteúdo), Tabela Nutricional, Massa, não possuir Indicação Medicamentosa e/ou Terapêutica e Idioma Português. Nos demais itens, foram verificados irregularidades, onde $50 \%$ dos rótulos não apresentaram numeração do Lote, Nomenclatura Botânica, Designação ("Chá de Erva-Doce") e Instruções de Preparo. Foi verificado, também, que $75 \%$ das amostras não especificavam Data de Fabricação e designação de Indústria Brasileira (no painel frontal). E $100 \%$ dos rótulos não especificavam os itens de Proteção da Luz, Frase "Isento de Registro" e Armazenamento de 1 Ano. 
Tabela 6 - Porcentagens de irregularidades nos rótulos analisados na amostras de funcho (Foeniculum vulgare)

\begin{tabular}{lc}
\hline \multicolumn{1}{c}{ Dados analisados } & \% de irregularidades \\
\hline Nome do fabricante & Todas Conforme \\
Logomarca da empresa & Todas Conforme \\
Endereço completo & Todas Conforme \\
CNPJ & Todas Conforme \\
Lote & 50 \\
Fabricação & 75 \\
Validade & Todas Conforme \\
"Indústria brasileira" (painel frontal) & 75 \\
Categoria do produto (conteúdo) & Todas Conforme \\
Nomenclatura botânica & 50 \\
Tabela nutricional & Todas Conforme \\
Proteção da luz & 100 \\
"Informação referente ao glúten” & 25 \\
Massa & Todas Conforme \\
Designação (“Chá de erva-doce") & 50 \\
Instruções de preparo & 50 \\
Não conter indicação medicamentosa e/ou terapêutica & Todas Conforme \\
Idioma português & Todas Conforme \\
Frase "isento de registro" & 100 \\
Armazenamento de 1 ano & 100 \\
\hline
\end{tabular}

Apesar de nenhum rótulo especificar a frase "Isento de Registro", estes estão conforme a legislação, já que a RDC no 278/05 dispõe que, quando não há indicações medicamentosas dos chás, não é necessário esse tipo de registro. Isso se deve ao fato dos chás serem considerados alimentos, pela Resolução n 23/00, o que promoveu uma queda na qualidade destes.

As amostras 02 e 04 (a granel) não especificaram o lote, importante no controle da produção, pois sua ausência dificulta a rastreabilidade de um lote reprovado.

Nenhuma das marcas informam a necessidade do material ser protegido da luz. Os óleos essenciais e outros componentes podem sofrer fotorreações quando expostos à luz solar, alterando a estabilidade físico-química do material, e comprometendo os efeitos esperados pelo uso do chá, assim como suas características organolépticas.

A não regularidade dos aspectos analisados nas amostras de funcho demonstra a falta de normatização e necessidade de maior controle da qualidade, comprometendo 0 uso seguro pelos consumidores, e afetarem o seu critério de escolha entre um produto e outro.

\section{CONCLUSÃO}

O funcho (Foeniculum vulgare) é muito utilizado pela população, tanto como alimento, mas também pela sua ação terapêutica, visto ser um produto natural de fácil acesso, baixo custo e possuir reconhecida ação farmacológica no tratamento de problemas gastrointestinais e possuir ação carminativa, digestiva e calmante, que é passada de geração para geração por intermédio do conhecimento 
popular.

No presente estudo, verificou-se que é necessária uma maior fiscalização pelos órgãos responsáveis, pois em todos os testes foram verificadas irregularidades nos chás comercializados dessa planta medicinal. Foram encontrados materiais estranhos, baixo índice de teor do óleo essencial, excesso de umidade, rotulagem inadequada e uma amostra com teor de cinzas acima do adequado e todas essas inconformidades podem ser prejudiciais aos usuários desse produto.

\section{REFERÊNCIAS}

BALBINO, E. E.; DIAS, M. F. Farmacovigilância: um passo em direção ao uso racional de plantas medicinais $e$ fitoterápicos. Revista Brasileira de Farmacognosia, v. 20, n. 6, p. 992-1000, dez. 2010.

BRASIL. Ministério da Saúde. Agência Nacional de Vigilância Sanitária. Resolução de Diretoria Colegiada - RDC № 23, de 15 de março de 2000. Dispõe sobre O Manual de Procedimentos Básicos para Registro e Dispensa da Obrigatoriedade de Registro de Produtos Pertinentes à Área de Alimentos. Diário Oficial da União, Poder Executivo, Brasília, DF, 2000.

Ministério da Saúde. Agência Nacional de Vigilância Sanitária. Resolução de Diretoria Colegiada - RDC № 259, de 20 de setembro de 2002. Dispõe sobre o regulamento técnico para rotulagem de alimentos embalados. Diário Oficial da União, Poder Executivo, Brasília, DF, 2002.

Ministério da Saúde. Agência Nacional de Vigilância Sanitária. Resolução de Diretoria Colegiada - RDC № 278, de 22 de setembro de 2005. Dispõe sobre o regulamento técnico sobre registro $e$ dispensa da obrigatoriedade de registro de produtos pertinente à área de alimentos. Diário Oficial da União, Poder Executivo, Brasília, DF, 2005.

Ministério da Saúde. Agência Nacional de Vigilância Sanitária. Rotulagem Nutricional Obrigatória: Manual de orientação aos consumidores saudável, 2008.

- Ministério da Saúde. Agência Nacional de Vigilância. Resolução de Diretoria Colegiada - RDC № 14, de 31 de março de 2010. Dispõe sobre o registro de medicamentos fitoterápicos. Diário Oficial da União, Poder Executivo, Brasília, DF, 2010.

Ministério da Saúde. Política nacional de plantas medicinais e fitoterápicos. Brasília: Ministério da Saúde, 2006.

Farmacopéia Brasileira 5a Edição,

Agência Nacional de Vigilância Sanitária. Brasília: Anvisa, 2010.

CARVALHO, L. M. et al. Caracterização da produtividade do funcho (Foeniculum vulgare Mill.) no sertão de Sergipe. Revista Brasileira de Plantas Medicinais, Botucatu, v. 13, n. esp., p. 527-532, 2011.

CUNHA, A. P.; DA SILVA, P. A.; ROQUE, O. R. Plantas e produtos vegetais em cosmética e dermatologia. Lisboa: Fundação Calouste Gulbenkian, 2004.

FALKOWSKIQ, G. J. S.; JACOMASSI, E.; TAKEMURA, O. S. Qualidade e autenticidade de amostras de chá de camomila (Matricaria recutita L. Asteraceae), Revista Instituto Adolfo Lutz, v. 68, n. 1, p. 64-72, 2009. 
LORENZI, H.; MATOS, F. J. A. Plantas da erva-doce (Foeniculum vulgare). 2003. medicinais no Brasil: nativas e exóticas. 2. 25f. Monografia (Especialização em Gestão ed. Nova Odessa, SP.: Instituto Plantarum, e Análise Ambiental). Universidade Estadual 2008. da Paraíba. Campina Grande, 2003.

LUCCA, P. S. R. et al. Avaliação farmacognóstica e microbiológica da droga vegetal camomila (Chamomilla recutita L.) comercializada como alimento em Cascavel

- Paraná, Revista Brasileira de Plantas Medicinais, Botucatu, v. 12, n. 2, p. 153-156, 2010.

MARREIRO, A. S. N.; TEIXEIRA, P. R. S.; SOUZA, R. P. Análise dos tipos de materiais estranhos encontrados em sachês de chá comercializados na cidade de Teresina - PI, Revista ACTA Tecnológica - Revista Científica, v. 5, n. 1, jan./jun. 2010.

RAMOS, C. L. C. Eficiência do extrato do melão de São Caetano (Momordica charantia) no crescimento populacional da SIMÕES, C. M. O. et al. Farmacognosia: da planta ao medicamento. 6. ed. Florianópolis: UFSC; 2007.

TINOCO, M. T.; MARTINS, M. R.; CRUZMORAIS, J. Actividade antimicrobiana do óleo essencial do Foeniculum vulgare Miller. Rev. de Ciências Agrárias, Lisboa, v. 30, n. 1, jan. Disponível em: http://www.scielo.gpeari.mctes.pt/scielo.php? script=sci arttext\&pid=S0871018X2007000100047\&lng=pt\&nrm=iso.

Acesso em: 23 ago. 2013.

ZARONI, M. et al. Qualidade microbiológica das plantas medicinais produzidas no Estado do Paraná, Revista Brasileira de Farmacognosia, v. 14, n. 1, jan-jun. 2004. 